\title{
A re-balanced scorecard: a strategic approach to enhance managerial performance in complex environments
}

\author{
Joseph H. Callaghan \\ School of Business Administration, \\ Oakland University, \\ Rochester MI 48309, USA \\ E-mail: callagha@oakland.edu
}

\author{
Arline Savage and Steven Mintz \\ California Polytechnic State University, \\ Orfalea College of Business, \\ San Luis Obispo CA 93407, USA \\ Fax: 805-756-6347 \\ E-mail: savage@calpoly.edu \\ E-mail: smintz@calpoly.edu
}

\begin{abstract}
This paper is a proposal to develop conceptual and practical frameworks for evolving corporations seeking to improve their managerial performance in complex environments with actionable strategies for dealing with social, environmental and corporate governance issues. These frameworks are coalesced by social contract theory that extends the traditional view of the firm as a nexus of contracts to a broader view of the firm as a nexus of social contracts. A re-balanced scorecard is proposed to induce and evaluate management performance that captures important dimensions and aspects of the frameworks established for firms strategically choosing to change their long term objectives to include those related to meeting their social contract obligations.
\end{abstract}

Keywords: balanced scorecard; corporate governance; legitimacy; management behaviour; management performance; social contract.

Biographical notes: Joseph Callaghan is a Professor of Accounting at Oakland University in Rochester, Michigan. He received his Doctorate in Accountancy from the University of Illinois at Urbana-Champaign. His expertise lies in the financial, managerial and accounting information systems (AIS) areas, across which he develops model-based valuation systems. Hs primary research areas include evaluating risk and performance of organisations, and reengineering legacy AIS. He has served as a Consultant for businesses in the areas of financial planning and valuation analysis, systems planning and risk assessment. 
Arline Savage is a Professor of Accounting and Deloitte Faculty Fellow at California Polytechnic State University, San Luis Obispo. She received her Doctorate from the University of Port Elizabeth (now Nelson Mandela Metropolitan University) in South Africa. Her areas of expertise are financial reporting, financial analysis, forensic investigations, and information systems. She has co-authored a book, Advanced Financial Accounting, and two Elsevier research monographs.

Steven M. Mintz is a Professor of Accounting in the Orfalea College of Business at California Polytechnic State University, San Luis Obispo. He received his $\mathrm{PhD}$ in Accounting from The George Washington University. $\mathrm{He}$ is the author of Ethical Obligations and Decision Making in Accounting: Text and Cases. He has had numerous papers published in the areas of business and accounting ethics, corporate governance, and accounting education.

\section{Introduction}

"Problems cannot be solved at the same level of awareness that created them"

-Albert Einstein

To achieve long-run sustainability, contemporary organisations need to go beyond the traditional shareholder-wealth-maximisation paradigm in which managerial performance and compensation are driven mainly by limited accounting-based financial measures, 'balanced' by customer, internal process, and employee learning-and-growth measures (i.e., the traditional balanced scorecard). Often these measures are merely leading indicators for improved financial performance and no fundamental shift in strategy takes place when adopting them.

Although, most agree that managers must now focus on longer-term organisational survivability rather than short-run profit maximisation (e.g., based on quarterly earnings per share), traditional managerial performance systems often do not include non-profit-maximisation rubrics. We propose a revised strategic framework that includes 'social contract obligations' among its long term objectives. To ensure that this strategic initiative is effective, organisations also need a managerial performance system that ensures compliance with the new organisational strategy - i.e., a system that balances the organisational benefits of market-based economic rewards with real spillover costs (i.e., negative economic externalities) incurred from sub-standard managerial behaviour and violations of social contracts.

The conceptual framework for such rests upon social contract theory and our view of the firm as a nexus of social contracts. This conception is an extension of the traditional Jensen-Meckling view of the firm as a nexus of economic contracts that established the groundwork for agency theory (Jensen and Meckling, 1976), which has been criticised for failing to consider the external social context surrounding a principal-agent relationship (Bruce et al., 2005). Our framework provides the basis for a managerial measurement system that better reflects the complexities faced by managers in balancing the various claimants to an organisation's resources. In particular, it focuses on: 
1 managerial behaviour

2 organisational legitimacy (organisational behaviour)

3 legal/regulatory processes (enforceable behaviour)

4 economic activity (micro-organisational behaviour; macro-societal behaviour).

Social contract theory embraces all four components of this conceptual framework. We also map the progression from this conceptual framework to a practical structure in the form of a re-balanced scorecard. Our goal is for the practical framework to lead toward the development of a managerial performance system for implementing this re-balanced scorecard to better measure, monitor and induce improvements in managerial behaviour in a multidimensional organisational environment for those organisations that have decided that it is in their long term best interest to pursue this strategy (see e.g., De Bettignies and Lépineux, 2009). Consequently, the re-balanced scorecard provides a framework to assist in using information to improve managerial decision-making and overall organisational performance (Akdere, 2009; Ravishankar and Pan, 2008; Choi et al., 2008).

Despite recent governmental interference in several US markets, most economists continue to believe that free-market economies still offer the best chance for wealth creation. However, there is also widespread recognition that pure laissez faire policies fail to incorporate real spillover costs. For example, pollution costs, the lack of property rights over some common resources, and excessive executive compensation for firms that receive government bailout funds all illustrate problems deserving governmental action through legal and regulatory mechanisms. Similarly, unethical conduct by one firm or even one individual - e.g., Bernard Madoff - can have severe economic, political and financial consequences to others.

In the USA, experts estimate that in the wake of Enron, WorldCom, etc., over \$3 trillion of losses in market equity capitalisation occurred over a two-year period due to the loss of investor confidence in the financial/capital markets. This does not include other indirect costs resulting from the related effects, such as general economic downturn, a loss of jobs, and government and litigation costs. More recently, the sub-prime mortgage debacle in the USA and the perceived unethical managerial behaviour in such firms as American International Group, Inc. (AIG) have had severe repercussions throughout the world. Moreover, a firm's survival and failure under crisis is not determined solely by their economic prospects, but by external political and social factors.

In the 1920s, President Calvin Coolidge said, "the business of America is business" and this is no truer today, even if the line between corporate US and the government becomes more obscure. It makes sense, therefore, to view a firm as a nexus of social contracts. The challenge going forward is how to monitor and incorporate the costs of managerial misconduct due to the violation of such social contracts, while preserving the general benefits derived from a market-based economy.

The purpose of this paper is to present the firm as a nexus of social contracts that permit the establishment of consistent conceptual and practical frameworks to induce and measure management behaviour in a multidimensional organisational environment that includes social, environmental and corporate governance issues. These frameworks are 
intended to lead to performance evaluation systems in the form of a re-balanced scorecard for monitoring and inducing improvements in managerial behaviour consistent with the contemporary organisational environments for organisations whose strategies include adoption of longer term measures of corporate success. This research is consistent with Chavan's (2009, p.405) insight into a more balanced scorecard that is effective in supporting a living, growing, and viable organisation.

This paper makes the following contributions. First, by viewing the firm as a nexus of social contracts, it permits a direct analysis of important business issues beyond profit motives. Second, this view (and the revised framework) encourages a longer-term orientation that seeks to assure firm survivability and sustainability. Third, we broaden the traditional shareholder focus to include non-traditional claimants who have social contracts with the firm. Fourth, from the new conceptual framework, we derive a re-balanced scorecard of managerial performance that better reflects the complex factors managers currently face to achieve the firm's long-term survivability and sustainability.

Regular internal-processes evaluate managers with balanced-scorecard metrics. As such, these processes are organisationally trapped within that manager's 'silo' - e.g., by measuring the throughput of a manufacturing department. An extension of this idea is to obtain performance evaluations from a manager's supervisor (up), subordinates (down), and co-managers (horizontal), hence completing a $360^{\circ}$ circle of feedback.

Though an improvement over traditional supervisor-only measures of performance feedback, $360^{\circ}$ assessments as usually implemented are still silo-trapped. Our assessment system extends the traditional $360^{\circ}$ process to a spherical assessment system that includes feedback from upstream process 'suppliers' and downstream 'customers', hence, completing the sphere. This transforms the traditional assessment from a 'hierarchically-oriented view of the firm' to a 'process-oriented view of the firm', informed by effective corporate governance systems.

We do not specifically prescribe the conditions under which an organisation should adopt our framework. In this sense, we are not prescribing this framework and its implementation generally, but we do specify an approach conditional upon the organisation's decision to change corporate strategy. Such decisions involve a deep understanding of the firm's industry, the industry's regulatory and legal environment, and a competitive analysis, including first-mover advantages following a firm's strategic choice. While these issues are pivotal to a particular organisation, they are beyond the scope of this study.

The paper proceeds as follows. In the next section, we develop the conceptual framework and discuss the notion of social contracts, which bind the components of the conceptual framework. Next, we discuss legitimacy theory, which provides the connection between managerial behaviour and the legal/regulatory components. After this, we introduce relevant economic theory in the context of a legal/regulatory environment. Thus, having established the major institutional aspects of the managerial performance system, we describe managerial behaviour within this context. We then present the practical framework using a balanced scorecard approach that implements the conceptual framework and suggests the use of various managerial measures. This bridges the gap between the purely theoretical and its pragmatic implementation, while attempting to maintain the integrity of both. Finally, we draw conclusions and make suggestions for further research. 


\section{The conceptual framework}

\subsection{Discussion of the framework}

The traditional view of the firm as a nexus of contracts consists of relationships primarily between owners and management (as agent of owner); between upper and lower management (and non-management employees); between management (as agent of owner) and creditors; and between management and customers and vendors. This view of profit maximising subject to legal constraints is beset with well-documented agency and information asymmetry problems (e.g., Saam, 2007), with management performance (and compensation) based mainly on the use of limited accounting-based financial measures, which are leavened (or 'balanced') by customer (external direct contract), internal process, and employee (employment contract) learning-and-growth measures in a traditional balanced scorecard environment. The intention is that these three dimensions will lead to improved financial measures. The traditional view relies on the use of financial measures to mitigate the main agency problem between management and owners.

This traditional view can be summarised as follows: managing (individual/agency behaviour or $m$ ) $\rightarrow$ legal/regulatory processes (enforceable behaviour or $r$ ) $\rightarrow$ economic activity (micro-organisational behaviour; macro-societal behaviour; $e$ ), from which we derive the following model:

$$
+\Delta m \Rightarrow-\Delta r \Rightarrow \Delta e
$$

In our view, effective managerial behaviour for evolving firms includes the faithful execution of the firms' social contracts. In this context, social contracts subsume traditional legal contracts (including abiding by tort standards). While minimally-required managerial behaviour in line with social contracts is enforceable by legal and regulatory systems, firm-legitimising behaviour that accounts for and incorporates spillover costs both pre-empts the need for what might otherwise be inefficient additional legal and regulatory changes and instils within the culture of the firm ethical behaviours that fulfil obligations, including those to non-traditional external stakeholders. The net effect of incorporating these spillover costs should preserve the efficient allocation of resources through pricing mechanisms at the economic level. Consequently, a balanced approach to the measurement and inducement of managerial behaviour is circumscribed by organisational legitimatisation, legal/regulatory and economic considerations. The retention of the benefits derived from a market-based economy is balanced against legal and regulatory obligations (e.g., compliance with Sarbanes-Oxley legislation in the US) and costs that would otherwise result if organisational legitimacy is not established through effective managerial behaviour. Figure 1 depicts the managerial behavioural, legitimisation behavioural, legal/regulatory enforcement, and economic action components of the social contract conceptual framework.

From this figure, we amend our view of the firm to: managing (individual/agency behaviour) $\rightarrow$ legitimisation (organisational behaviour) $\rightarrow$ legal/regulatory processes (enforceable behaviour) $\rightarrow$ economic activity (micro-organisational behaviour; macro-societal behaviour). From this, we derive the following model:

$$
+\Delta m \Rightarrow+\Delta l \Rightarrow-\Delta r \Rightarrow+\Delta e
$$


Figure 1 Social contract conceptual framework

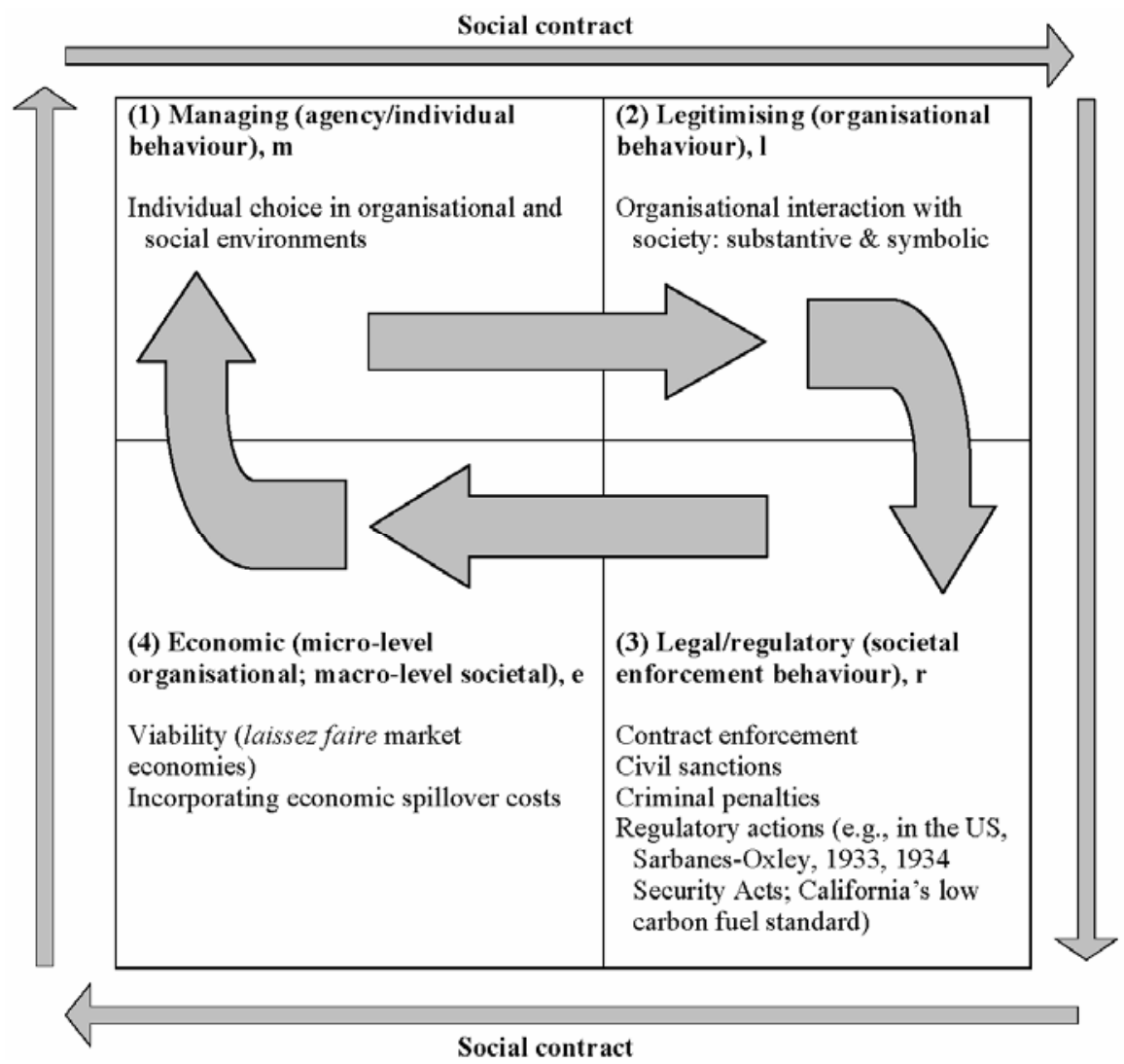

By focusing on social contracts (as a superset of traditional legal contracts), we include the legitimacy problem (social agency) alongside traditional agency problems, and we add the social dimension to legal constraints. We measure economic behaviour more broadly to include spillover costs (and therefore sustainability) within the societal framework. We also expand managerial performance measures to include indirect external stakeholders, internal process, and learning-and-growth measures.

We posit that this balanced approach would induce positive changes in agency/individual managerial behaviour $(m)$, which would lead to an increase in organisational legitimacy $(l)$. This increase in legitimacy would reduce the need for potentially inefficient societal control of spillover costs by excessive legislation and/or regulation $(r)$, leading to a balanced macroeconomic policy that maximises the benefits associated with a more laissez faire resource allocation of the private sector while explicitly and concurrently incorporating spillover costs to the firm (e). At the organisational level, improvement in managerial performance should lead to positive changes in organisational legitimacy through a reduction in the risk-adjusted discount rate applicable to a firm's cash flows. By the same token, management misbehaviour (e.g., the granting of sub-prime mortgage loans to unqualified home buyers) would lead to an increase in risk (Cormier et al., 1993; Gunthorpe, 1997; Hamilton, 1995; Pava and 
Krausz, 1996). In addition, benefits associated with pre-empting costly legal and regulatory actions caused by improvement in legitimacy would inure to the organisation.

\subsection{The social contract}

Organisations and society coexist in a social-contractual relationship (e.g., Keeley, 1988). The idea of social contracting, consisting of explicit or implicit agreements among members of society to act with reciprocal responsibility in their relationships, can be traced back to Plato (428BC-348 or 347BC). Other advocates of the social contract include philosophers Thomas Hobbes (1588-1679), John Locke (1632-1704), and Jean Jacques Rousseau (1712-1778). The social contract assumes a societal consensus of what is, and is not, desirable behaviour by members (including corporations) of a society. It not only represents an explicit set of formally specified obligations that are enforceable through legal and regulatory mechanisms, but also a set of indirect, implicit responsibilities towards those who directly or indirectly conduct business with an organisation [Donaldson, (1982), pp.32-36]. In our view, social contract theory is comprised of both legal/regulatory obligations that are institutionally enforceable and implicit social and environmental obligations that can be met through effective managerial behaviour. Effective enforcement of the firm's social contracts through a balanced management evaluation process informed by the commitment to ethical values would lead to increased organisational legitimacy.

\subsection{Organisational legitimacy theory}

All organisations owe their continued existence to the mandate of society-at-large [Shocker and Sethi, (1974), p.67; Gray et al., (1991), p.15; Mathews, (1993), pp.26-27, (1998), p.25]. Legitimisation is thus a necessary long-term management strategy for maintaining the trust of the society that authorises and validates the privileges inherent in the corporate form of doing business [for an investigation of over 500 Norwegian companies, see Vidaver-Cohen and Brønn (2008)]. As part of the social system, firms utilise resources that might be otherwise allocated. Although, in market-based economies much deference is given to the markets to make resource allocation decisions, excess spillover costs need to be systematically incorporated in order to establish long-term economically efficient allocations. We use Dowling and Pfeffer's (1975, p.122) definition of organisational legitimacy.

Organisations seek to establish congruence between the social values associated with or implied by their activities and the norms of acceptable behaviour in the larger social system of which they are part. Insofar as these two value systems are congruent we can speak of organisational legitimacy. When an actual or potential disparity exists between the two value systems, there will exist a threat to organisational legitimacy.

For example, Shell Oil's Nigerian and Brent Spar scandals culminated in a change to Shell's underlying business principles, in which the organisation formally committed itself to supporting 'fundamental human rights in line with the legitimate role of business' [Harveson and Corzine, (1997); Donaldson and Dunfee, (1999), pp.1-5]. Consequently, organisational legitimacy is philosophically rooted in the notion of a social contract between organisations and society [Belkaoui, (1984), p.44]. 
Neither profit-making nor legal compliance alone establishes organisational legitimacy [Mathews, (1993), p.30]. Dowling and Pfeffer (1975, p.124) discuss the existence of three partially interdependent sets of organisational behaviours, namely, those that are economically viable, legal, and legitimate. Our conceptual framework formally integrates a fourth interactive component, effective managerial behaviour, which relies on underlying ethical values and effective corporate governance and is the vehicle for the implementation of the three interdependent factors. Thus, our framework establishes the firm as a nexus of social contracts, coalesced by social contract theory, which is effectively managed by managers who establish an ethical tone at the top and whose performance is measured in a balanced, consistent and comprehensive manner.

Legitimacy theorists predict recurrent conflicts between management and society over the form of legitimisation activities, which consists of two types. The first type is substantive activity, where management materially changes its behaviour, and/or manages to change social norms and values because the society that the firm depends upon for critical resources generally prefers substantive responses [Ashforth and Gibbs, (1990), pp.178-182; Suchman, (1995), p.576]. The second type is symbolic activity, where management does not change its behaviour, but attempts to portray its activities in a manner in which they appear to be compatible with social norms and values (Ashforth and Gibbs, 1990, p.180; Pfeffer, 1981, p. 28). In the past, management has generally favoured offering symbolic assurances rather than substantive action (Ashforth and Gibbs, 1990, p.182; Suchman, 1995, p.585), since the former reflects the traditional shareholder-centric view of the firm. Since our motivation is to develop a performance system that motivates substantive managerial legitimisation activities, our focus is on substantive strategies. These strategies are briefly summarised below:

1 Role performance: Management adapts goals, methods of operation, and/or outputs to conform to the performance expectations of the society upon which it depends for critical resources [Ashforth and Gibbs, (1990), p.178; Dowling and Pfeffer, (1975), p.127].

2 Coercive isomorphism: Management blends evolving societal norms and values into its organisational structure in order to conform to society's collectively valued purposes and institutionalised practices [DiMaggio and Powell, 1983; Meyer and Rowan, 1977; Suchman, (1995), p.581].

3 Altering socially institutionalised practices: Management attempts to communicate an altered definition of social legitimacy which reflects its activities. This is the most difficult strategy to implement [Dowling and Pfeffer, (1975), p.127].

Our approach is to implement a role performance strategy that temporally induces coercive isomorphism. While altering socially institutionalised practices is possible, it has rarely been achieved and thus is not included in our framework.

In summation, there is a need for management performance-based evaluation systems to motivate behaviour that establishes some level of substantive organisational legitimacy. While some substantive legitimisation may merely reflect self-interested economic behaviour (in that it may avoid certain legal/regulatory sanctions), it might also reflect changes in the organisational culture that recognises the broader obligations under the social contract. It also may specifically incorporate spillover costs that are detrimental 
to both society and the firm itself in the long-term. Organisational legitimacy thus provides the logical connection between effective management behaviour of individuals and the social legal/regulatory environment that the contemporary firm faces.

\subsection{The legal/regulatory environment and economic theory}

\subsubsection{Legal/regulatory}

The legal/regulatory environment concurrently promotes and constrains economic activities in market-based economies. Through the enforcement of private property rights and private commercial contracting, private sector economic activity is facilitated. These enforcement activities (or threats thereof) reduce the risk associated with engaging in market-based transactions. Thus, the efficient allocation of scarce economic resources associated with market-based economies has as its underpinning certain legal institutional arrangements. These arrangements include constitutional (e.g., US interstate commerce and 'taking' clauses), legislative (e.g., the US Uniform Commercial Code and Internal Revenue Code) and common law provisions. Conversely, the legal environment, along with its regulatory apparatus, proscribes certain private economic activity. Examples include anti-trust, labour, environmental and discrimination (e.g., price, racial, age, and gender) law. In addition, tort law (the standards enforcing 'reasonable' behaviour and duties with the threat of monetary damages for breaches of those duties) and criminal law (with the threat of fines and/or imprisonment for criminal conduct) deter or prohibit certain types of individual and business conduct.

Of course laws and standards evolve temporally. In terms of legitimacy, as societal expectations of individual and organisational behaviour changes, behaviour that once was induced by legitimisation can be induced by new court rulings, legislation, and regulation, such as the Sarbanes-Oxley Act that was enacted following the accounting frauds at Enron and WorldCom and a house bill in the USA that would tax executive bonuses at $90 \%$ for firms in receipt of at least $\$ 5$ billion in federal bailout funds, as described in A Wall Street Journal report aptly entitled 'Wall street shudders as lawmakers take aim at the industry's pay system' [Lucchetti and Lattman, (2009), p.A6]. These changes are intended to and in fact do impose costs upon the organisation and the economic system generally.

Costs imposed by legal/regulatory mechanisms may be economically inefficient for several reasons. First, compliance costs are incurred by all, not just to those who have exhibited the undesirable behaviour. Second, enforcement necessarily has elements of randomness in that the proscribed behaviour may be hard to observe and consequently enforcement resources themselves have to be allocated. Third, proscription by definition bars certain conduct, whereas the societal interest may lie in inducing positive action for which legal/regulatory systems are not particularly well-designed. Finally, it may not be the 'wrong doers' who necessarily bear these costs, but the consumers of the organisation's products and services may have to bear the burden. A good example is the cost of complying with Sarbanes-Oxley legislation. According to the findings of the first annual Directorship/RHR International Board Survey (2004) of corporate boards, compliance costs increased 77\% between 2003 and 2004, the first two years following enactment of the law. In fact, general electric spent $\$ 30$ million on internal control requirements in 2004. Many have criticised the internal control (Section 404) 
requirements for imposing costs upon companies that have been complying with relevant laws all along. Support exists for such criticisms with respect to the recent financial crisis brought on by the greed of some managers. One may wonder where the internal controls were to prevent and detect the risky behaviour that led to the $\$ 700$ billion bailout to be paid by the public.

For all of these reasons, it may be in society's interest not to use the legal/regulatory system, but rather to allow for self-regulation through legitimisation processes. That is, dynamic balancing is necessary to achieve desired societal behaviour between legal/regulatory mechanisms and social contract enforcement. In either case, the organisation can be viewed as the nexus of implicit and explicit social contracts. The question becomes what the better enforcement mechanism is for these organisational duties. This becomes the crux between the legal/regulatory and the organisational legitimacy components, with each having a differential impact on the market-based economy.

\subsubsection{Economic theory}

Economic systems can theoretically run the continuum from pure laissez faire (i.e., 'invisible hand') to purely controlled economies (where central governmental planning leads to resource allocation such that no private property rights adhere to individuals). To date, it appears that market-based economies have been more successful at generating wealth than either socialised or communist systems. The sine qua non of market-based economies is the establishment of market mechanisms that through an unregulated pricing process allocates scarce economic resources. Individuals and organisations motivated by economic profit manifest their preferences (and private information) in the formation of market prices. Societies with market-based economies have a keen interest in permitting markets to function well. However, a lack of clearly delineated property rights causes markets to ignore the incorporation of the full cost of the economic resources utilised into prices. The classic example is of a manufacturer that pollutes a river as part of its production process because nobody owns the rights to the clean water in the river, resulting in spillover cost being incurred by others or society at large. Further, the costs of other externalities, such as an interstate transportation system, are not fully incorporated into measurable organisational costs. To some extent, the Pigovian taxes attempt to incorporate these costs, but the cause and effect is very noisy and inherently inefficient.

Thus, the failure of laissez faire policies to incorporate spillover costs on the one hand, versus economic incentives lost by excessive or inefficient legislation and regulation on the other hand, necessitates a balancing of interests to achieve optimal social arrangements. This balancing would require legislative/regulatory action where persistent failure of organisations to attend to all of their social contractual obligations through the maintenance and changing of managerial behaviour in a dynamic social system exists.

In summary, varying economic systems, legal/regulatory institutional arrangements and legitimacy theory play important roles in establishing the nature, scope, benefits and costs of social contracting. Proper consideration and balancing of these components provide a conceptual basis for determining and understanding what a particular society demands with regard to individual managerial behaviour. 


\subsection{Effective management behaviour}

To attain improved substantive legitimacy that reduces the need for inherently inefficient regulation or legislation, while incorporating spillover costs, requires a change in individual manager behaviour. Organisations, markets, and institutions are aggregations of individual behaviour (Barnard, 1938; De Gaus, 1997). Moreover, in the legal/regulatory area, moral- and/or culturally-based standards of business behaviour need to go beyond the letter of the law to fulfil the intent of the law or higher ethical values. Thus, for both short-term self-interest and long-term survival, business organisations need to systematically incorporate processes that improve the managerial performance of their people.

If an improved managerial component can be incorporated into the traditional view of the firm as a profit maximiser, then the theory of the firm can transform from a limited agency view as a 'nexus of contracts', to the more encompassing view of the firm as a 'nexus of social contracts', within a realistic institutional environment. Therefore, the conceptual development provides a framework for considering the most important constructs for the logical sequence of changed individual manager behaviour. Changed manager behaviour, informed by ethical values that help to set the proper tone, leads to changed organisational behaviour at the microeconomic level. The firm will then interact with the legal/regulatory institutional environment in a market-based economy to preserve the best aspects of private market mechanisms, while systematically embedding spillover costs.

Having first established the conceptual framework relating management behaviour to organisational legitimacy and then to its effect upon both the legal/regulatory and economic environments, we turn to the practical measurement system that implements these conceptual constructs.

\section{The practical framework}

\subsection{Introduction}

While the first framework proposes re-balancing the traditional balanced scorecard at a theoretical level, the practical framework proposes specific measures that can be used by actual organisations to measure the new dimensions of the re-balanced scorecard. Given the strategic approach of this research, traditional empirical validation of our proposed model is not possible at this time. However, the practical framework proposed does systematically capture many real-world phenomena that would otherwise be seemingly unrelated. Currently, corporate initiatives related to, e.g., sustainability, carbon management, corporate social disclosures, and control of spillover costs, generally, are observable phenomena that our framework can capture and systematise. Otherwise, these phenomena would not only appear to be ad hoc but incapable of being measured in a way that would give management specific incentives consistent with their organisation's strategy. As our proposed framework is adopted by organisations, empirical validation of this approach would be possible, especially by comparing external performance measures of adopting organisations against otherwise similar non-adopting organisations. 
The introduction of indirect stakeholders as a scorecard category, and its associated suggested measures, offers organisations to systematically think about and implement these underlying strategic initiatives. Moreover, the framework provides a way for organisations to motivate managers to implement these initiatives and achieve their ends. Specifically, managers' performance is measured by the re-balanced scorecard on both the indirect stakeholder and associated learning-and-growth dimensions that are consistent with chosen corporate strategy.

\subsection{Stakeholder taxonomy}

The previous section includes the integration of the four dimensions of the conceptual framework: improved managerial behaviour constructs, legitimacy theory, legal/regulatory institutional arrangements, and balanced economic systems. Organisational legitimacy, while internally attempted through improved individual management behaviour (guided by ethical values, supported by effective corporate governance systems, and induced by an effective management evaluation system), is externally conferred by various coalitions of stakeholders. The legitimacy component of the social contract theory permits consideration of quasi contracts with indirect stakeholders emphasising ethical behaviour of management. The separation of owners from management in the contemporary corporation manifests itself by the delegation of shareholder authority to an elected board of directors, who set policy and appoint executive management, who, in turn, hire middle and lower management. Consequently, the board of directors represents the boundary between external and internal direct stakeholders. Corporate governance issues are raised on this boundary. Table 1 provides taxonomy of the types of stakeholders.

Table 1 Extended stakeholder taxonomy, including examples

\begin{tabular}{|c|c|c|}
\hline & Direct stakeholders & Indirect stakeholders \\
\hline \multirow[t]{6}{*}{$\begin{array}{l}\text { External to } \\
\text { firm }\end{array}$} & Shareholders & $\begin{array}{l}\text { SEC and other governmental } \\
\text { regulators }\end{array}$ \\
\hline & Creditors & Competitors \\
\hline & Customers & Environmental coalitions \\
\hline & Vendors & Animal rights coalitions \\
\hline & External auditors & Other activist coalitions \\
\hline & Markets & Public-at-large \\
\hline \multirow[t]{4}{*}{$\begin{array}{l}\text { Internal to } \\
\text { firm }\end{array}$} & $\begin{array}{l}\text { Management (includes Board of } \\
\text { Directors) }\end{array}$ & \multirow{4}{*}{$\begin{array}{l}\text { Organisational adaptation based on all } \\
\text { feedback (by adding indirect } \\
\text { stakeholders) }\end{array}$} \\
\hline & Audit committee & \\
\hline & Employees & \\
\hline & Internal 'customers and vendors' & \\
\hline
\end{tabular}

The external/internal dimension in Table 1 delimits the information available and the intensity of the contractual relationship, whereas the direct/indirect dimension goes to the enforceability and magnitude of economic claim that the group has on the organisation. Traditional measures of organisational performance focus on direct claimants with public information being required for direct external stakeholders (traditional nexus of contracts) 
and are well-developed. Conversely, measures for external indirect stakeholders are not well developed (i.e., the social aspect added to traditional nexus of contracts). Collectively, these measures will monitor overall organisational compliance with its nexus of social contracts.

\subsection{The conventional balanced scorecard}

In the 1990s, Kaplan and Norton (1992, 1993, 1996a, 1996b, 1996c) introduced the balanced scorecard, which is an internal assessment, improvement and reporting system. It ties a typical measurement system to an entity's strategic plan and supplies key indicators for management to perform its function. The successful implementation of this management system turns strategy into action. The balanced scorecard remains one of the most popular management tools and has gained global prominence (Aravamudhan and Kamalanabhan, 2007a, 2007b, 2009; Korhonen and Baumgartner, 2009; Lee and Lai, 2007; Punniyamoorthy and Murali, 2009).

The conventional scorecard (see Figure 2) measures performance by combining financial measures with non-financial measures from the following perspectives:

1 financial

2 customer

3 internal business processes

4 learning-and-growth.

Figure 2 The conventional balanced scorecard (see online version for colours)

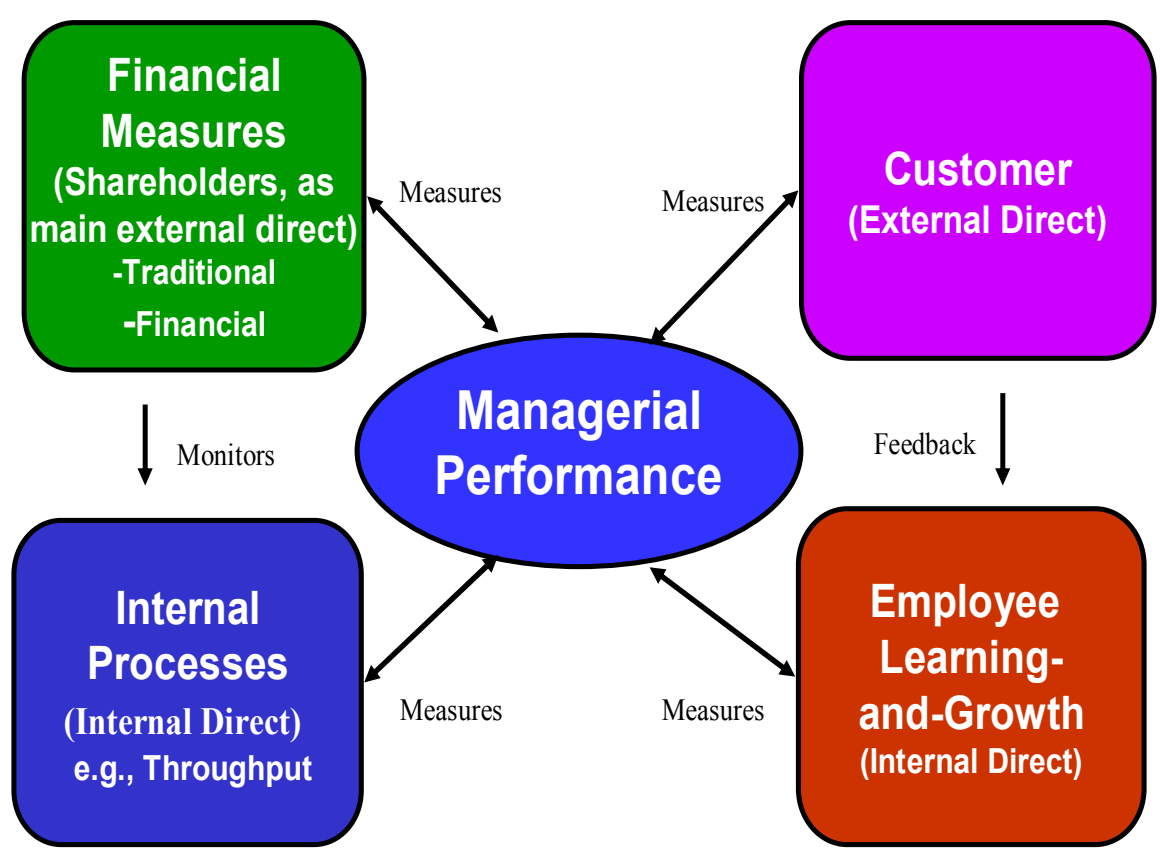


The balancing is done by including non-financial measures (customer, internal business processes, and learning-and-growth) with historical financial accounting measures. Inducing improved performance to meet the objectives of the strategic plan requires monitoring of the entity's obligations to its traditional stakeholders, the most common being the stockholders, creditors, customers, and employees. In turn, a thorough assessment of the organisation's business processes is needed to align these obligations, and with the business strategy. Learning-and-growth opportunities facilitate improvements to business processes, and also require that employees change their behaviours when necessary.

\subsection{The re-balanced scorecard}

Figure 3 depicts the major dimensions of our re-balanced scorecard approach to the development of an improved managerial rating system. From the corporation's perspective, to induce improved managerial behaviour requires an analysis of both the organisation's obligations under its social contracts and the public's perception of its managerial performance. This includes the traditional view of obligations to its stakeholders. In turn, the organisation needs a thorough assessment of its internal processes to align them to its expanded obligations. Finally, this requires that individual organisational members change their behaviours via organisational learning-and-growth opportunities, given the dynamic nature of the social, contractual relationships and the corresponding changes in obligations.

Figure 3 Dimensions of the re-balanced scorecard (see online version for colours)

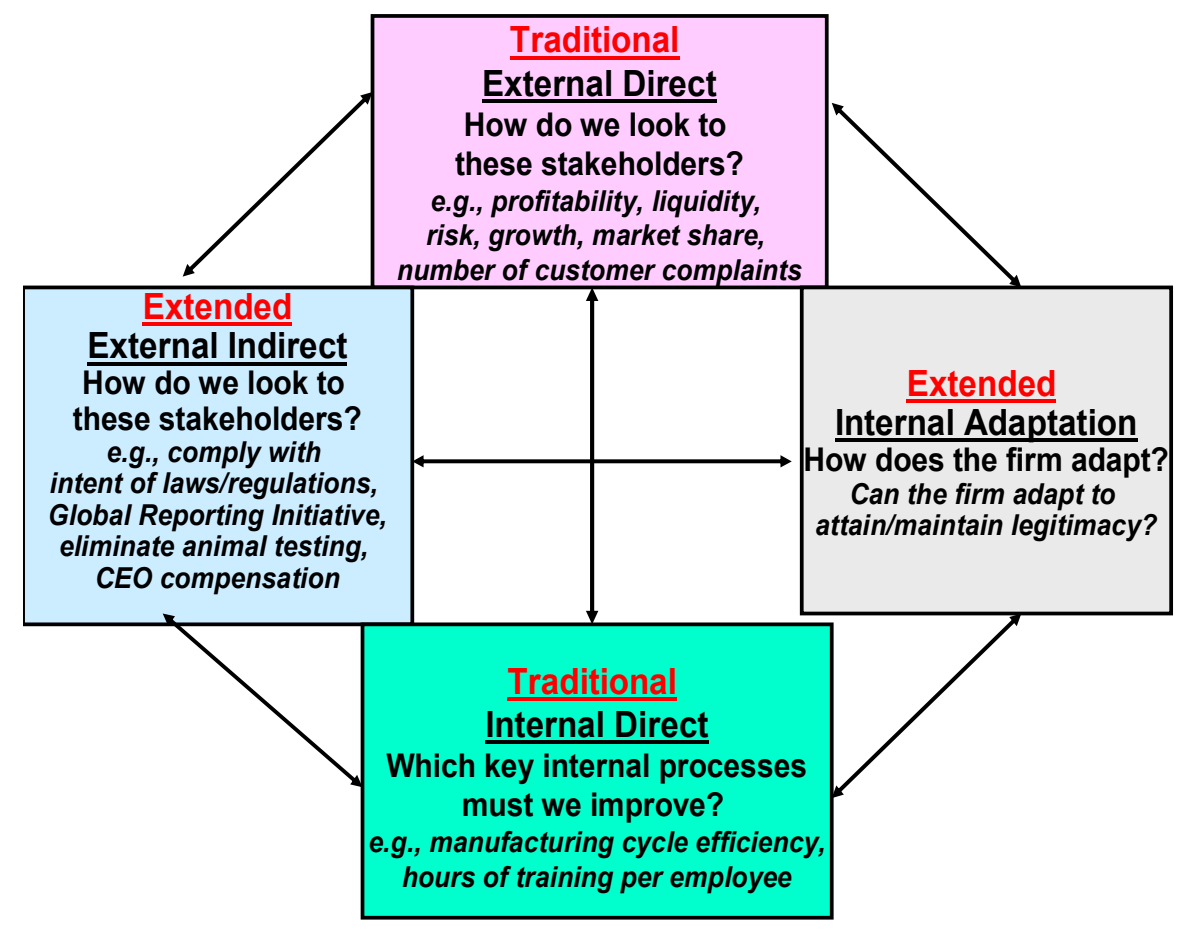


This practical framework adapts the widely-used 'balanced scorecard approach' (Kaplan and Norton, 1992, 1993, 1996a, 1996b, 1996c) to operationalise the conceptual framework. Practical measurements are outlined that would permit the actual monitoring of organisational managerial performance and suggests a path for inducing temporal improvements in this performance.

In the dimensions of the re-balanced scorecard presented in Figure 3, we substitute the traditional 'customers' category with 'indirect, external stakeholders', and now include customers under direct external stakeholders, along with investors and vendors. Consequently, we expand traditional financial measures to include metrics on all external stakeholders and we add a new dimension for indirect external stakeholders. This dimension permits the systematic incorporation of measures related to indirect stakeholders of the firm. Often, through regulatory or political action, these groups bring performance considerations that would otherwise be ignored by managers. By including this dimension, we lift the time horizon that managers face by including emerging, possibly strategic issues. After all, the 'customers' of managerial performance are the various classes of stakeholders, and from each group we can extract various measures of performance. Thus this framework provides a change from narrowly defined direct stakeholders (e.g., managers and customers) to wider categories of stakeholders.

Figure 4 depicts the re-balanced scorecard for monitoring and changing organisational legitimacy with the internal methods available to the organisation to monitor and change its managerial performance.

Figure 4 The re-balanced scorecard (see online version for colours)

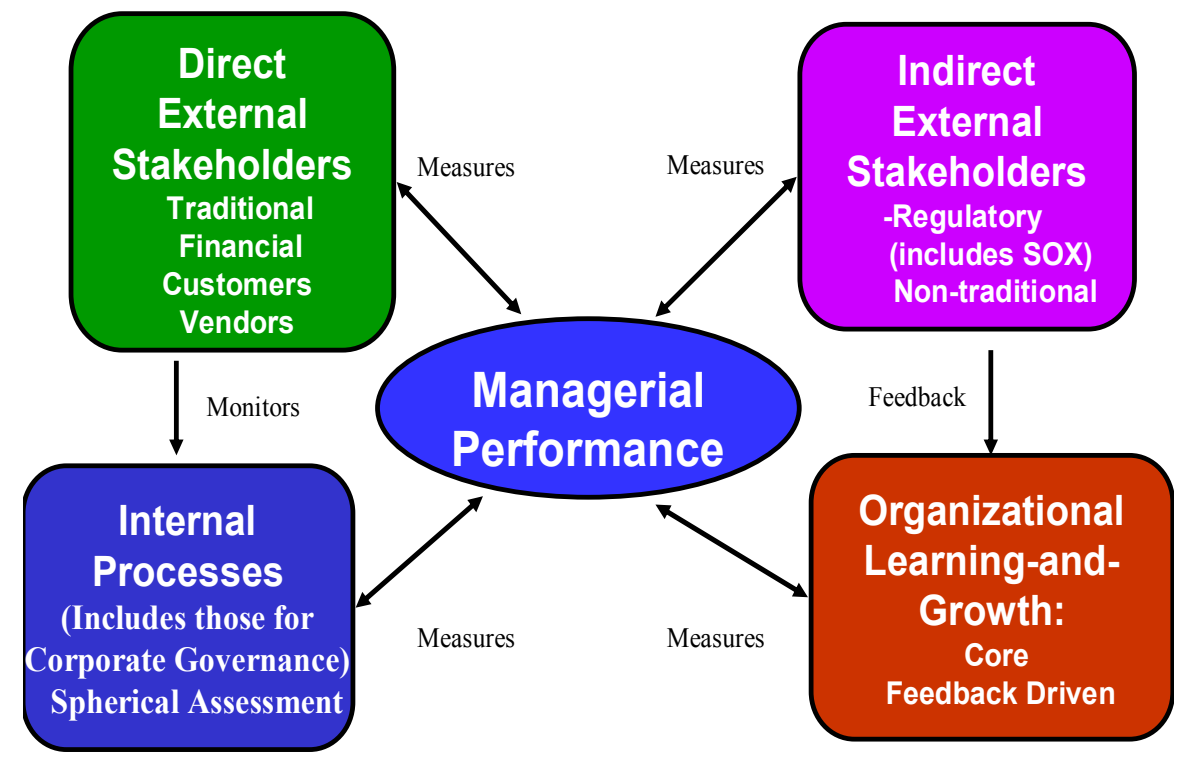

Organisational performance has external measures related to direct external stakeholders (traditional), balanced by external measures related to indirect external stakeholders. These external measures are coupled with analogous and extended internal process measures that can be broken down on a direct and indirect basis (from $360^{\circ}$ to spherical assessment). Internal direct absorbs the traditional internal processes category, but 
extends this category by inclusion of assessment measures from both internal 'suppliers' and 'customer'. The traditional learning-and-growth dimension has been changed to capture organisational adaptation that is used as a mechanism to motivate managers and employees to learn, assess and implement the feedback obtained from all stakeholders and internal processes of our re-balanced scorecard.

The standard financial analysis measures related to direct external stakeholders would be gathered and standardised. For example, traditional profitability, liquidity, leverage, and growth measures arising from financial statement analysis can be performed and compared to industry norms. These analyses, especially those related to financial distress, operating risk and financial risk would give insight not only into shareholder return prospects, but also to risk associated with financial environments conducive to potential unethical behaviour including earnings management techniques that are designed to report earnings based on management's desires and not as it should be reported under generally accepted accounting principles.

Unsound financial environments and business models are breeding grounds for earnings and balance sheet manipulations, a manifestation of unethical financial reporting. In addition, earnings manipulation measures (e.g., the overuse of accruals relative to an industry average), financial risk and an analysis of financial analysts' forecasts properties are additional sources of empirical information bearing on the ethical risk environment. Customers and vendors, now included as direct external stakeholders would thus have measures (e.g., sales returns, warranty work and survey data) included in this category.

Indirect, external stakeholders would vary by organisation. For example, an oil refinery would rank an environmental coalition higher than would a non-manufacturing service company. Once important coalitions are identified, indirect and direct empirical measures of these groups' perceptions could be gathered in several ways including the number of adverse media reports, SEC complaints, pending law suits, class action lawsuits, and surveyed perceptions of coalition members.

For internal direct measures, along with traditional internal process measures such as throughput, manufacturing efficiency, and product quality measures, we would include formal spherical assessment measures. Feedback from indirect stakeholders, along with feedback from traditional direct stakeholders, could include formal questionnaire-based survey results as measurements.

The legal/regulatory and legitimacy components of the conceptual framework can be better operationalised by viewing them from the perspective of various stakeholder types that form coalitions (or agents), and who perform the conference of legitimisation, with certain types of stakeholder coalitions having more power than others (Mitchell et al., 1997). The traditional balanced scorecard is directed at managerial performance and the balancing is done by including non-financial measures (i.e., internal processes, customer, and employee learning-and-growth measures). The importance of transforming the traditional 'customers' into 'indirect external stakeholders' in our re-balanced scorecard should be underscored. After all, the 'customers' of managerial performance are the various classes of stakeholders, and from each group we can extract various measures of performance. Under our approach, organisational performance has external measures related to direct external stakeholders (traditional), balanced by external measures related to indirect external stakeholders that are coupled with internal processes, involving organisational learning-and-growth measures built on a foundation of ethics and supported by corporate governance mechanisms. 
Table 2 Re-balanced scorecard taxonomy and examples of measures

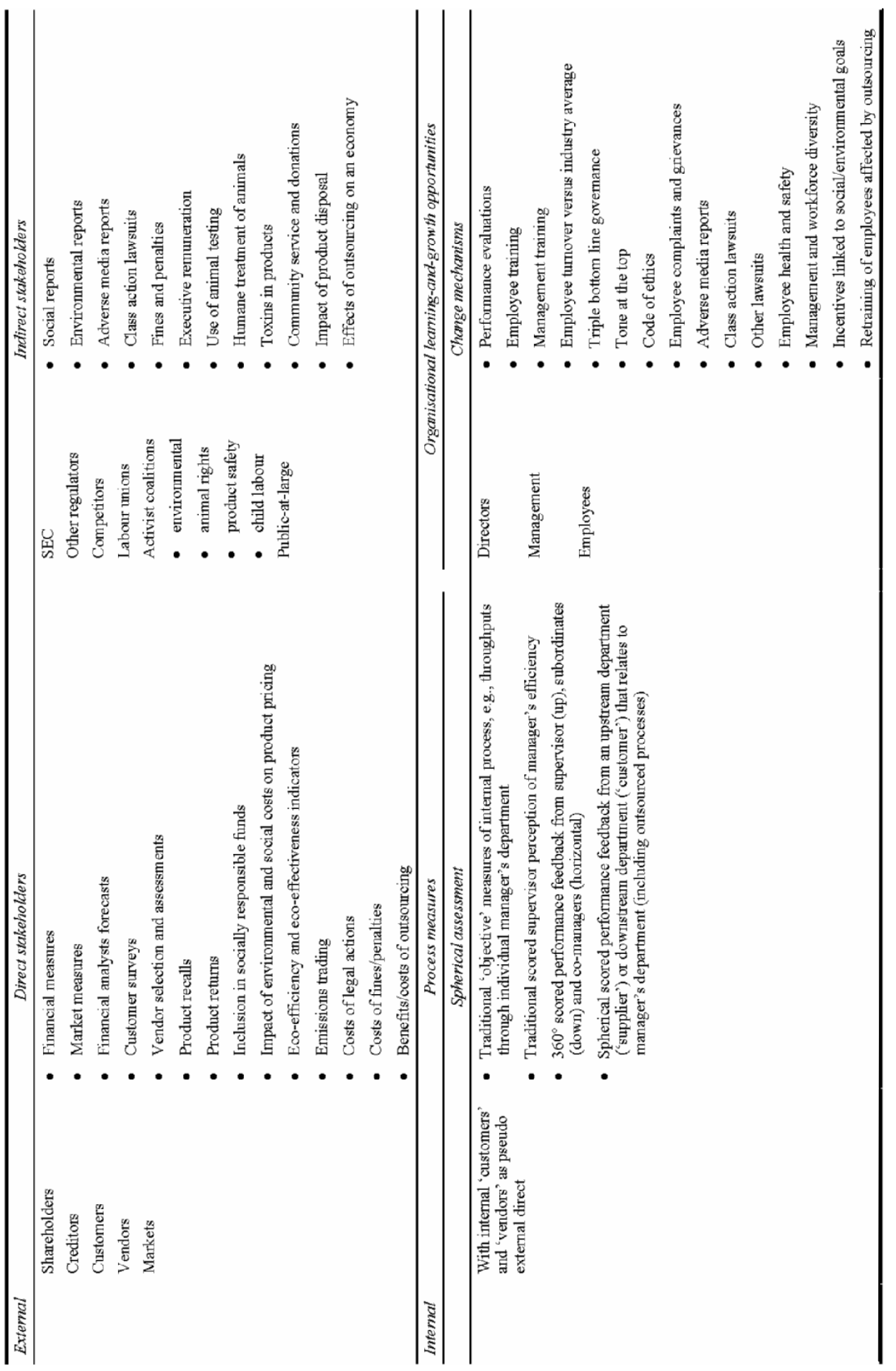


Table 2 shows the four measurement groups that will be employed. These are:

1 external, direct measure derived using finance and financial accounting methods

2 external, indirect measures, including, e.g., the perceptions of various indirect coalition groups, say environmentalists organisations

3 internal process measures (including those for corporate governance) using spherical assessment techniques

4 organisational learning-and-growth opportunities for the organisation's board and employees that induce observable changes in managerial conduct.

The resulting managerial performance measures are then constructed by weighting the various measures from the four dimensions.

Table 2 provides re-balanced scorecard taxonomy with examples of measures for each category. These measures are not prescriptive, but will be chosen by the firm. Measures are also not necessarily mutually exclusive to each category. Under the first category, the standard financial analysis measures related to direct, external stakeholders, i.e., shareholders and creditors, would be gathered and standardised. For example, traditional profitability, liquidity, leverage (risk), and growth measures arising from financial statement analysis can be performed and compared to industry norms. These analyses, especially those related to financial distress, operating risk and financial risk would give insight not only into direct claimant return prospects, but also to risk associated with financial environments conducive to potential unethical behaviour. Unsound financial environments and business models may be breeding grounds for earnings and balance sheet manipulations, a manifestation of unethical financial reporting. In addition, earnings manipulation measures (e.g., the overuse of accruals relative to an industry average), financial risk measures (e.g., firm beta), and an analysis of financial analysts' forecasts properties are additional sources of empirical information bearing on the ethical risk environment.

Second category measures would entail the systematic identification of important indirect, external claimants. This would vary by organisation. For example, from a stakeholder perspective, an oil refinery would rank an environmental coalition higher than would a non-manufacturing service company. Once important coalitions are identified, indirect and direct empirical measures of these groups' perceptions could be gathered in several ways, as suggested by the legitimacy literature. The number of adverse media reports, SEC complaints, pending law suits, class action lawsuits, and surveyed perceptions of coalition members are possible candidates for inclusion as elements of this dimension.

One approach to the implementation of the internal processes and learning-andgrowth dimensions of the balanced scorecard is the use of some assessment instrument. Proper assessment of internal processes leads to implied learning-and-growth opportunities for organisational improvement. The hierarchical orientation of the $360^{\circ}$ assessment, though an improvement on traditional assessment methods, has limitations. Being hierarchical, feedback is limited to internal feedback-providers, while excluding internal and external vendors and customers. This precludes a process-oriented assessment approach. The use of our spherical assessment approach can overcome these limitations. 
On the internal processes dimension, our spherical assessment instrument improves the traditional $360^{\circ}$ instruments in two ways. First, the important categories and constituent elements of managerial behaviour can be identified from the literature. For example, under a category of 'managerial leadership' might be an element such as: 'The manager communicates the importance of individual ethical behaviour'. A participant could then evaluate the manager on a survey scale, based upon his/her observation of this behaviour. Participants would include the multiple subordinates, multiple co-workers, and the supervisor of the target manager. Second, to make the $360^{\circ}$ process 'spherical' would entail including as participants the 'suppliers' and 'customers', whether they be internal or external to the organisation. These external stakeholders are generally concerned about fair treatment and reliability. The systematic use of the spherical assessment results would give rise to individual, departmental, divisional and organisational measures of managerial performance. Gap analysis at the elemental level would give rise to manager-tailored learning-and-growth opportunities.

Simpler measures of this dimension could include indicators like whether or not there is an organisational managerial policy, whether or not employees are required to sign such a policy, and so forth. All of the measures would assume management 'buy-in' to the new measurement system, the commitment to ethical values, and the acceptance of costs imposed by the monitoring processes. The management of the monitoring process itself is critical. Ideally, board sponsorship and management by the audit committee would be mandated, with management-independent consultants performing the actual monitoring tasks.

The spherical assessment internal monitoring process would give rise to a natural mapping of managerial performance gaps to training and development in terms of specific learning-and-growth opportunities. For example, if a manager were deemed deficient on the 'knowledge of corporate managerial policies' element, then training on this specific dimension would ensue. Subsequent spherical assessments could measure the effectiveness of the training as well as the training measures themselves. Thus the internal process could be both iterative and dynamic, with the dynamic aspect picking up new elements as the environment changes. Consequently, learning-and-growth opportunities provide a mechanism to improve internal processes. Improved processes and behaviour would presumably improve stakeholders' satisfaction. Improved societal and stakeholder satisfaction increases legitimacy and improves long-term financial performance of the organisation, and at the aggregate level the market-based economy itself.

This framework also provides the basis for externally validated organisational managerial performance. Similar to bond rating agencies, external measures could provide a managerial rating component. Governance metrics rating agencies such as Governance Metrics International rate corporate governance characteristics of participating companies. Other rating agencies are The Corporate Library, ISS Corporate Governance Quotient, and TRUE Course-Shark Repellent.

In conjunction with direct internal observations of managerial behaviour, externally validated traces of such behaviour would be also captured. These external observations would measure phenomena like earnings management, lack of auditor independence, and financial environments generally conducive to unethical behaviour.

It is one thing to identify the important dimensions and empirical measures of an organisation's balanced managerial assessment. It is quite a challenge, however, to 
properly weigh the measures within and across these dimensions. Each organisation would have to struggle with these problems. On the other hand, established rating agencies, e.g., Standard and Poors for bond ratings, have confronted these difficult issues. The use of multivariate statistical techniques, along with post hoc analysis of failures, would improve weighting schemes over time. Finally, good faith attempts to measure managerial performance trump no attempt at all, if there is a recognition that an organisation's success and ultimate viability depend upon societal acceptance of its managerial performance in fulfilling its explicit and implicit obligations.

\section{Conclusions and further research}

To arrive at a more balanced management evaluation system that more fully incorporates spillover costs, organisations should be more proactive in changing and maintaining individual manager behaviour to attain substantive legitimacy that fulfils the social contract. This should lead to a more balanced economic system that continues to use private incentives and market allocation mechanisms in a politically stable environment, while reflecting the values and full costs of its economic activities. This paper offers conceptual and practical frameworks to help achieve this social goal.

The progression from the conceptual framework to the practical framework (re-balanced scorecard) is as follows: Managerial behaviour manifests itself in the internal processes, which are improved by learning-and-growth opportunities for management and employees and spherical assessment of suppliers and customers, all reflecting the ethical values of the organisation. Legitimacy (and lower legal/regulatory costs/risks) is manifested by perceptions of indirect external stakeholders. Finally, traditional external stakeholders provide the macroeconomic measures.

If implemented well, our re-balanced scorecard should force management to articulate a coherent strategy built on a commitment to ethical behaviour that is to be communicated throughout the organisation, and the feedback loop will make the evaluation process a dynamic one. Managerial measures are more likely to be actionable and consistent with the organisation's strategy. Additionally, the portfolio of measures will reduce gaming problems. More specific benefits of the re-balanced scorecard include increased shareholder value via risk reduction, reduced legal exposure to negligence and criminal liabilities, reduced insurance premiums, decreased regulatory costs, reduced spillover costs, and improved corporate image and citizenship. Possible problems are lack of corporate buy-in, culture shock/resistance, management push for measures they do relatively well on, and potential gaming via side agreements.

Subsequent phases of this research include finding appropriate metrics for monitoring organisational managerial performance and inducing temporal improvements in this performance; assigning appropriate weights to these metrics; doing ex-post analysis; and developing and assessing the usability of a computer information system to implement the re-balanced scorecard. A further direction for research could take a Galbraithian perspective on this same issue within the broader context of entrepreneurial capitalism's evolution towards the advanced industrial state of today. 


\section{References}

Akdere, M. (2009) 'The role of knowledge management in quality management practices: achieving performance excellence in organizations', Advances in Developing Human Resources, June, Vol. 11, pp.349-361.

Aravamudhan, S. and Kamalanabhan, T.J. (2007a) 'An AHP study on the critical factors for balanced scorecard implementation in Indian organisations', International Journal of Business Innovation and Research, Vol. 1, No. 4, pp.387-403.

Aravamudhan, S. and Kamalanabhan, T.J. (2007b) 'Identifying balance in a balanced scorecard system', International Journal of Learning and Change, Vol. 2, No.4, pp.386-404.

Aravamudhan, S. and Kamalanabhan, T.J. (2009) 'Adoption of management innovations: the case of balanced scorecard', International Journal of Strategic Change Management, Vol. 1, No. 3, pp.231-238.

Ashforth, B.E. and Gibbs B.W. (1990) 'The double-edge of organizational legitimation', Organization Science, Vol. 1, No. 2, pp.177-194.

Barnard, C. I. (1938) The Functions of the Executive, Harvard University Press, Cambridge, MA.

Belkaoui, A. (1984) Socio-Economic Accounting, Quorum Books, Westport, CT.

Bruce, A., Buck, T. and Main, B. (2005) 'Top executive remuneration: a view from Europe', Journal of Management Studies, Vol. 42, No. 7, pp.1493-1506.

Chavan, M. (2009) 'The balanced scorecard: a new challenge', Journal of Management Development, Vol. 28, No. 5, pp.393-406.

Choi, B., Poon, S.K. and Davis, J.G. (2008) 'Effects of knowledge management strategy on organizational performance: a complementary theory-based approach', The International Journal of Management Science, Vol. 36, No. 1, pp.234-251.

Cormier, D., Magnan, M. and Morard, B. (1993) 'The impact of corporate pollution on market valuation: some empirical evidence', Ecological Economics, Vol. 8, No. 2, pp.135-155.

De Bettignies, H-C. and Lépineux, F. (2009) 'Can multinational corporations afford to ignore the global common good?', Business and Society Review, Vol. 114, No. 2, pp.153-182.

De Gaus, A. (1997) The Living Company, Harvard Business School Press, Boston, MA.

DiMaggio, P.J. and Powell, W.W. (1983) 'The iron cage revisited: institutional isomorphism and collective rationality in organizational fields', American Sociological Review, Vol. 48, No. 2, pp.147-160.

Directorship/RHR International Board Survey, (2004) 15 November, available at: http://www.rhrinternational.com/Abstracts/2004-board-of-directors-survey.aspx.

Donaldson, T. (1982) Corporations and Morality, Prentice-Hall, Englewood Cliffs, NJ.

Donaldson, T. and Dunfee, T.W. (1999) Ties that Bind: A Social Contracts Approach to Business Ethics, Harvard Business School Press, Boston, MA.

Dowling, J. and Pfeffer, J. (1975) 'Organizational legitimacy: social values and organizational behaviour’, Pacific Sociological Review, Vol. 18, No. 1, pp.122-138.

Gray, R.H., Owen, D.L. and Maunders, K.T. (1991) 'Accountability, corporate social reporting, and the external social audits', Advances in Public Interest Accounting, Vol. 4, pp.1-21.

Gunthorpe, D.L. (1997) 'Business ethics: a quantitative analysis of the impact of unethical behaviour by publicly traded corporations', Journal of Business Ethics, Vol. 16, No. 5, pp.537-543.

Hamilton, J.T. (1995) 'Pollution as news: media and stock market reactions to the toxics release inventory data', Journal of Environmental Economics and Management, Vol. 28, No. 1, pp.98-113.

Harveson, P. and Corzine, R. (1997) 'In defense of international reputations', Financial Times, 31 October, p.16, London. 
Jensen, M.C. and Meckling, W.H. (1976) 'Theory of the firm: managerial behaviour, agency costs, and ownership structure', Journal of Financial Economics, Vol. 3, pp.305-360.

Kaplan, R.S. and Norton, D.P. (1992) 'The balanced scorecard: measures that drive performance', Harvard Business Review, January-February, pp.71-79.

Kaplan, R.S. and Norton, D.P. (1993) 'Putting the balanced scorecard to work', Harvard Business Review, September-October, pp.134-142.

Kaplan, R.S. and Norton, D.P. (1996a) The Balanced Scorecard, Harvard Business School Press, Boston, MA.

Kaplan, R.S. and Norton, D.P. (1996b) 'Linking the balanced scorecard to strategy', California Management Review, Vol. 39, No. 1, pp.53-77.

Kaplan, R.S. and Norton, D.P. (1996c) 'Using the balanced scorecard as a strategic management system', Harvard Business Review, January-February, pp.75-85.

Keeley, M. (1988) A Social-Contact Theory of Organizations, University of Notre Dame Press, Notre Dame, IN.

Korhonen, J. and Baumgartner, R.J. (2009) 'The industrial ecosystem balanced scorecard', International Journal of Innovation and Sustainable Development, Vol. 4, No. 1, pp.24-42.

Lee, C-L. and Lai, S.Q. (2007) 'Performance measurement systems for knowledge management in high technology industries: a balanced scorecard framework', International Journal of Technology Management, Vol. 39, Nos. 1/2, pp.158-176.

Lucchetti, A. and Lattman, P. (2009) 'Wall Street shudders as lawmakers take aim at the industry's pay system', The Wall Street Journal, 20 March, p.A6.

Mathews, M.R. (1993) Socially Responsible Accounting, Chapman and Hall, London.

Mathews, M.R. (1998) 'Accounting to a wider society: towards a mega-accounting theory', forum paper presented at The Annual Meeting of the American Accounting Association, New Orleans, LA.

Meyer, J.W. and Rowan, B. (1977) 'Institutionalized organizations: formal structure as myth and ceremony', American Journal of Sociology, Vol. 83, No. 3, pp.340-363.

Mitchell, R.K., Agle, B.R. and Wood D.J. (1997) 'Toward a theory of stakeholder identification and salience: defining the principle of who and what really counts', Academy of Management Review, Vol. 22, No. 4, pp.853-886.

Pava, M.L. and Krausz, J. (1996) 'The association between corporate social-responsibility and financial performance: the paradox of social cost', Journal of Business Ethics, Vol. 15, pp.321-357.

Pfeffer, J. (1981) 'Management as symbolic action: the creation and maintenance of organizational paradigms', Research in Organizational Behaviour, Vol. 3, pp.1-52.

Punniyamoorthy, M. and Murali, R. (2009) 'A framework to arrive at a unique performance measurement score for the balanced scorecard', International Journal of Data Analysis Techniques and Strategies, Vol. 1, No. 3, pp.275-296.

Ravishankar, M.N. and Pan, S.L. (2008) 'The influence of organizational identification on organizational knowledge management', The International Journal of Management Science, Vol. 36, No. 1, pp.221-234.

Saam, N.J. (2007) 'Asymmetry in information versus asymmetry in power: implicit assumptions of agency theory?', Journal of Socio-Economics, Vol. 36, No. 6, pp.825-840.

Shocker, A.D. and Sethi, S.P, (1974) 'An approach to incorporating social preferences in developing action strategies', in Sethi, S.P. (Ed.): The Unstable Ground: Corporate Social Policy in a Dynamic Society, pp.67-80, Melville Publishing, California.

Suchman, M.C. (1995) 'Managing legitimacy: strategic and institutional approaches', Academy of Management Review, Vol. 20, No. 3, pp.571-610.

Vidaver-Cohen, D. and Brønn, P.S. (2008) 'Corporate citizenship and managerial motivation: Implications for business legitimacy', Business and Society Review, Vol. 113, No. 4, pp.441-475. 